Boštjan Kravanja

\title{
Med plesnim studiem in družabnim plesiščem: o solidarnosti in praksah vzajemnosti v svingovskih plesnih skupnostih
}

Ključne besede: plesne skupnosti, popularna kultura, solidarnost, hierarhični odnosi, prakse vzajemnosti

DOI: $10.4312 /$ ars.8.1.58-78

\section{Uvod}

V ZDA in v številnih državah Evrope, pa tudi v Kanadi, Avstraliji, Novi Zelandiji in v nekaterih državah Azije in Južne Amerike se od 80. let ${ }^{1}$ dalje pojavljajo številne skupnosti, ki gojijo stare džezovske in svingovske ${ }^{2}$ plese (Lindy Hop Today, 2014). V popularno kulturo so ponovno uvedle ples v paru, ki je za več desetletij izginil iz subkultur (Renschaw, 2002, 72-73), v njihovem okviru pa lahko posameznik izraža pripadnost določeni obstranski sceni, ne da bi pri tem tvegal, da ga bo širše družbeno okolje zaradi tega stigmatiziralo. ${ }^{3}$

Obdobja preporoda različnih popularnokulturnih slogov se navadno pojavijo kot reakcija na »visoke« ali komercialne popularnokulturne oblike. Poleg spontanosti in neformalnosti poudarjajo predvsem specifično tradicijo. $\mathrm{V}$ tematskih klubih in na festivalih, ki jih razvijejo, je za razliko od zgolj pasivnega konzumiranja glasbe (nastopajoči in občinstvo) poudarek na soustvarjanju scene in življenjskega sloga ${ }^{4}$ (po Frith, 1996, 39-41). Številni mednarodni festivali, plesne delavnice in izmenjave

1 Ko bom v članku navajal desetletja, bo to vedno pomenilo 20. stoletje.

2 Sving (angl. swing) bom v besedilu dosledno slovenil, v pridevniških oblikah pa bom uporabljal oblike »svingovski«, »svingovci« itd., da s tem razlikujem s »svingerski« in »svingerji«, kar je uveljavljeno za označevanje skupnosti, ki prakticira lahkotnejše spolno življenje. Za različne druge tuje glasbene in plesne zvrsti bom v nominativu in sklonih sicer ohranjal izvirno različico zapisa, $\mathrm{v}$ pridevniških oblikah pa jih bom slovenil. Standard povzemam po Muršič (2000, 13, op. 2).

3 V okviru svingovstva sicer obstajajo tudi posamezne bolj uporniške scene (na primer rokenrolerske in rokabilijske), toda najmnožičnejši svingovski tokovi se navidezno ničemur ne upirajo in so usklajeni z nekaterimi »retro« usmeritvami sodobne mode in popularne kulture (glej Reynolds, 2011).

4 Pojma scena in življenjski slog sta za razliko od "podkulture« in »urbanega plemena« bolj odprta, ker opredeljujeta začasno »identifikacijsko polje« ter »kulturno ločene in označene vrste dogodkov«, ki so "situacijski« in v ospredje postavljajo »akterje, ki vstopajo vanje, se gibljejo po njih ter izstopajo« (po Muršič, 2000, 254). 
(angl. swing exchange), ki jih navadno na domačem terenu organizirajo vodilni člani in plesni učitelji posameznih scen, so tudi ena od osnovnih oblik združevanja plesalcev ${ }^{5}$ svinga.

Ples je kot standardiziran način kolektivnega poslušanja, občutenja in odzivanja na glasbo neločljiv del popularnoglasbenih scen (Frith, 1996, 139 in 141-142), vendar so plesne scene v tem smislu specifične, ker se posameznik ne more kar "prepustiti glasbi«, ampak se mora plesa najprej (na)učiti. ${ }^{6}$ Tako so plesne scene navznoter »organizirane okoli ekskluzivnosti« (Frith, 1996, 9), ker svoje plesalce formalno razvrščajo po plesnih ravneh, ${ }^{7}$ hkrati pa so tudi izrazito inkluzivne, ko gre za potencialne odjemalce plesnih učnih ur. ${ }^{8}$

Komercializacija in institucionalizacija svingovske plese vse bolj uniformirata in tako na eni strani predstavljata skorajda popolno predvidljivost festivalskih scen, na drugi pa s tem povečujeta mobilnost plesalcev in pestrost njihovih plesnih izkušenj. $\mathrm{Na}$ svingovskih scenah se za »dober ples«, podobno kot pri džezovskih glasbenikih (glej po Frith, 1996, 52-53), za idealno šteje dober performans in ne teorija. Vprašanja tehnike in "pravilnosti« izvajanja plesa so sicer pomembna, hkrati pa se za naprednejše ravni poudarja »improvizacijo« in izvirne načine zapuščanja konvencionalnih figur, slogov in gibov (angl. out of the box). Ker plesna tehnika zaradi tovrstnega vrednotenja ne predstavlja končnega cilja učenja, za konvencionalno participacijo na scenah pa se je je danes treba formalno učiti, so tudi učitelji svingovskih plesov v osnovi v nasprotju sami s seboj, saj tečajnike učijo "pravilne« izvedbe plesa, hkrati pa jih spodbujajo k individualni izvirnosti kot tistemu idealu svinga, ki ohranja vez $z$ avtentičnimi plesalci. ${ }^{9}$

Člani globalne svingovske plesne skupnosti ta pomen individualne izvirnosti plesnega izraza (o tem glej Williams, 2011a) utrjujejo z vrednotenjem vrhunskih

5 To obliko bom uporabljal, ko bom v besedilu govoril o plesalkah in plesalcih nasploh, ko pa bo govora o plesalkah in plesalcih v kontekstu plesne prakse, jih bom ločeval glede na njihove plesne vloge.

6 Nekdaj se je svingovski ples razvijal prek posnemanja in eksperimentiranja na družabnih plesiščih ter prek nekvalificiranega prenosa znanja med plesalci, danes pa je učenje svingovskih plesov organizirano. Alternativno učenje svingovskih plesov je sicer tudi možno (na primer samoučenje iz videoposnetkov), a se ga poslužujejo predvsem že izkušeni plesalci.

7 Formalne ravni plesnega znanja so: začetna, nadaljevalna, nadaljevalno višja, višja, višja + in vabljena raven. Na družabnem plesišču te ravni načeloma niso pomembne, čeprav se novinci na sceno navadno integrirajo prek »sošolcev« s tečaja.

8 Svingovske scene večino novincev dobijo prek posredovanja med znanci, gotovo pa k spodbujanju zanimanja veliko doprinesejo tudi pogosti promocijski nastopi tako na samih scenah kot $\mathrm{v}$ najrazličnejših drugih javnih kontekstih. Svingovski plesi se pojavljajo tudi v nekaterih komercialnih oglasih, pa tudi na koncertih svingovske glasbe, ki jih občasno organizirajo podjetniki razvedrilne industrije in gostinstva za široke množice.

9 S tem mislim na ameriške svingovske plesalce iz zlatega obdobja svinga 30. in 40. let, ki ga bom v članku podrobneje obdelal v razdelku o zgodovini svingovskega preporoda. 
svingovskih nastopov (na primer na socialnih omrežjih in na samih dogodkih). »Kulturni kapital« (Bourdieu, 1984), ki izhaja iz tega vrednotenja, je seveda relevanten predvsem znotraj svingovskih institucij, kjer se plesno znanje pridobiva skozi tečaje, komunikacijo med učiteljem in učencem ter individualno treniranje plesnih parov, utrjuje pa se tudi na družabnem plesišču, ki ga sestavljajo zelo različni, bolj ali manj izučeni plesalci, ki skozi vzajemne plesne prakse spontano generirajo različne skupine in znanstva/prijateljstva.

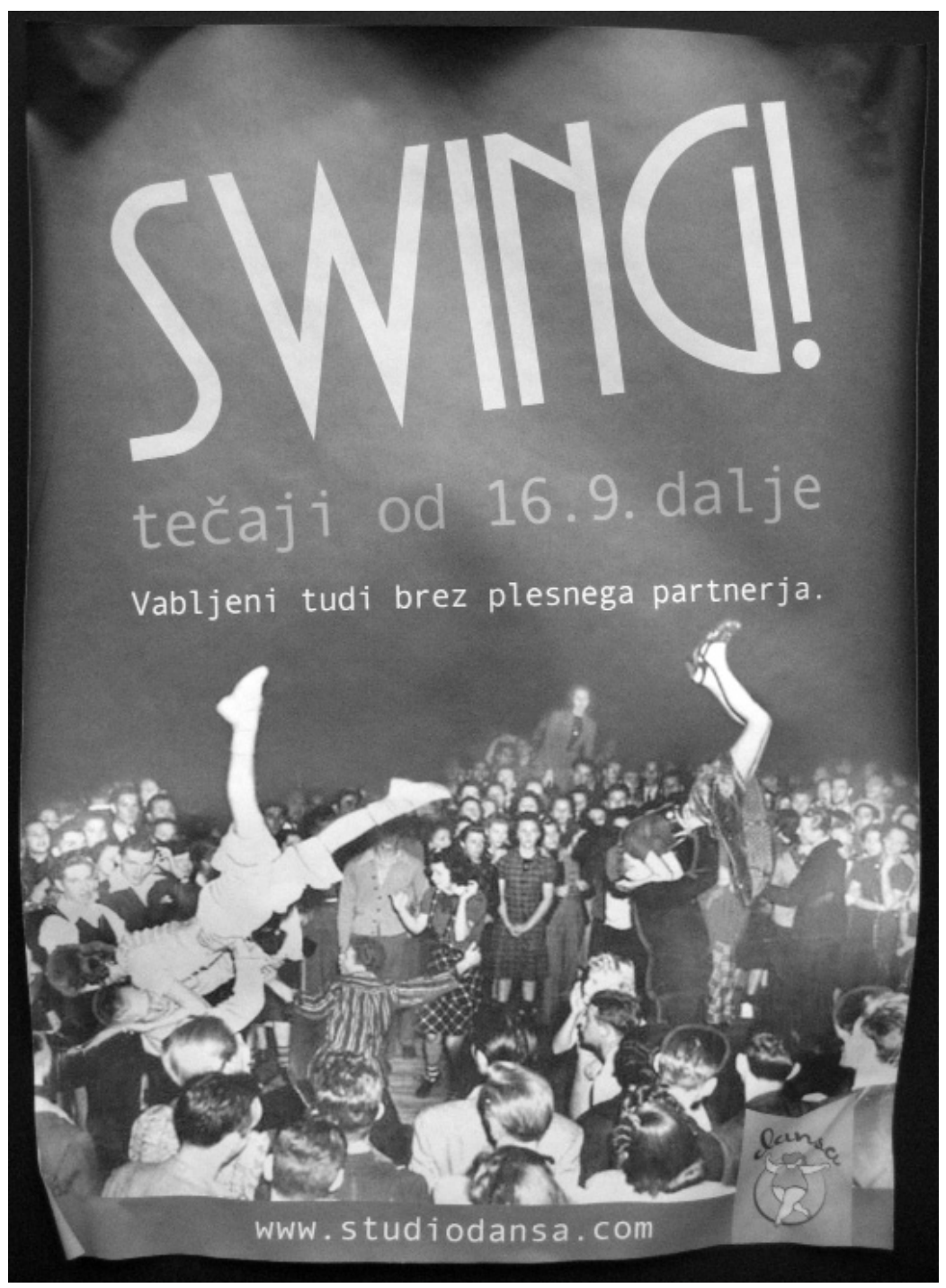

Slika 1: Oglas za začetek sezone tečajev leta 2013 pri ljubljanskem svingovskem društvu Studio dansa. Foto: B. Kravanja. 
Tako so na eni strani vidnost, razpoložljivost in predvidljivost pomemben del globalne svingovske plesne skupnosti, na drugi strani pa se lahko svingovske plesne scene na mikroravneh medsebojno precej razlikujejo. Njihov pomen je treba, tako kot pri večini popularnokulturnih scen, »demistificirati« (Frith, 1996, 14) ter ga iskati pri samih plesalcih in ne v plesu kot kulturnem artefaktu (Frith, 1996, 13).

V pričujočem članku se bom osredotočil na vprašanje, na kakšne načine se $\mathrm{v}$ hierarhično organiziranem svingovstvu generira solidarnost in kako se solidarnostni odnosi vzpostavljajo skozi vzajemne prakse na družabnem plesišču. V ospredju bo torej razmerje med institucionalnimi ravnmi svingovstva in spontano plesno vzajemnostjo plesalcev, kjer se solidarnostni in hierarhični odnosi med njimi vzpostavljajo tako glede na raven obvladovanja plesa kot tudi skozi lokalne hierarhije »okusa" (Bourdieu, 1984). Nekateri plesalci preferirajo določene plesne sloge in zvrsti ter se tako povezujejo $\mathrm{v}$ določene somišljeniške kroge ali pa do plesa, scene in svingovskega življenjskega sloga na splošno zavzemajo bolj sproščen, bolj resen ali kakorkoli specifičen odnos in se tako po nenapisanih pravilih bolj ali manj zavestno ločujejo od drugih.

Kljub tej potencialni raznolikosti $\mathrm{v}$ odnosu do svingovstva pa sem na podlagi lastne udeležbe na svingovskih scenah ${ }^{10}$ prepričan, da so sam ples, njegove vsebine in konvencionalne prakse bistvene za razumevanje sodobne popularnosti svingovstva. To bom v članku pojasnil skozi predstavitev nekaterih njegovih zgodovinskih in družbenih okvirov, ki so na eni strani pripeljali do inkluzivno-solidarnostne podobe globalne svingovske skupnosti, na drugi pa do omenjenih vzajemnih praks, ki na številnih lokalnih scenah generirajo drugo vrsto solidarnosti. Ta se ne podreja nujno dominantni solidarnostni ideologiji svingovske industrije, ampak se dinamično vzpostavlja skozi notranjo solidarizacijo in hierarhizacijo plesalcev in plesalk na raznolikih družabnih plesiščih.

V nadaljevanju bom najprej opredelil raznolikost družabnih plesišč na primeru slovenskih svingovskih scen, pri kasnejši analizi omenjenih dveh vrst solidarnosti pa se bom omejil na večinski svingovski ples, ki v Evropi od 80. let naprej sledi »avtentični« tradiciji newyorškega lindihopa.

10 Svingovstva se aktivno udeležujem od leta 2007 in do danes sem se pobliže spoznal z vsemi svingovskimi scenami v Sloveniji ter obiskal številne festivale v tujini. Pričujoči članek je torej prej derivat teh izkušenj kot rezultat intencionalnega etnografskega terenskega dela. Kljub temu pa sem bil v času pripravljanja in pisanja tega članka na svingovske scene pozoren na drugačen način kot sicer in ob tem izvedel tudi številne, $v$ posamezna vprašanja usmerjene neformalne pogovore $\mathrm{z}$ različnimi akterji na scenah. 


\section{Oris raznolikosti in porajanja slovenskih svingovskih scen}

Prvi zametki svingovstva so se v Sloveniji pojavili leta 2005, ko je v Ljubljano prišel plesni učitelj in koreograf, ameriški Slovenec Sajles Šinkovec, in vzgojil prvo generacijo plesalcev, katere del se je kasneje priključil širšemu mednarodnemu preporodu svingovstva. ${ }^{11} \mathrm{~V}$ Ljubljani pa so dejavni tudi tisti (kasnejši) Sajlesovi učenci, ki nadaljujejo njegovo zamisel nekoliko bolj eklektične in v novi sving zazrte scene. Ta se deloma povezuje tudi $z$ rockabillyjem in ikonografijo plesanja rock 'n' rolla, tako da so tudi njeni oblačilni slogi nekoliko drugačni od »urejenega vintiškega sloga oblačenja, ki je v navadi pri večinskem mednarodnem svingovstvu. ${ }^{12}$

Slovenska svingovska scena šteje med dvesto in tristo aktivnih plesalcev in je danes dokaj dobro usidrana tudi v Mariboru (društvo Swingbrats), posamezne iniciative pa se pojavljajo tudi v drugih krajih, kot na primer na Ptuju, v Kranju, Celju, Kamniku, Brežicah in še marsikje. Manjše scene lahko zaživijo tudi za dlje časa, kar je v veliki meri odvisno od plesalcev, učiteljev plesa in didžejev iz osrednjih scen, ki navadno pomagajo ustvarjati njihov osnovni okvir.

V Ljubljani ostaja svingovstvo razdeljeno na dve medsebojno različni sceni. Prva se danes združuje okoli društva Studio dansa in deloma društva Vintage, druga pa okoli društva Swing Kids in članov plesne skupine No sweat. Ta razdelitev je dokaj groba, ker ne zajema številnih drugih interesnih skupin, ki oblikujejo različne mini scene, ${ }^{13}$ in ker potegne ločnico tam, kjer za številne posameznike v praksi ne obstaja tako ostro. Z zornega kota posameznega plesalca je torej danes na svingovsko ali rokenrolsko glasbo mogoče plesati skoraj vsak dan, s tem da številna plesna prizorišča v Ljubljani vznikajo na novo, se nekaj časa vzdržujejo, zamrejo, se preselijo drugam itd. Enako je $z$ vse številčnejšimi festivali in delavnicami, ki privabijo plesalce iz vseh scen, ne glede na to, kam čutijo, da sicer pripadajo.

Kljub načelni vzajemni inkluzivnosti in prepustnosti pa se večina plesalcev gornje ločnice vendarle vsaj zaveda (glej tudi Baggia, 2008, 52). Prvi, torej tisti, katerih

11 Podrobno zgodbo uvajanja oživljenega svinga v Slovenijo je zgledno in po mojem mnenju verodostojno opisal Grega Baggia v svoji diplomski nalogi (2009, 48-49 in 51-56). Z nekoliko drugačnimi poudarki in $\mathrm{v}$ dodatnih podrobnostih jo je $\mathrm{v}$ nedavnem intervjuju razložil tudi eden pionirjev in aktualnih vodij slovenskega lindihopa Nejc Zupan (poslušaj Swingopis podcast 2014).

12 Za osrednje prireditve festivalov navadno velja vintiška oblačilna koda. Z množičnostjo svingovstva se sicer ti standardi sproščajo in usmerjajo tudi $\mathrm{k}$ bolj sproščenim oblačilnim slogom (angl. casual style), ki pa še vedno pogosto vključujejo elemente iz klasičnega obdobja ameriškega svinga 20., 30. in 40 . let.

13 Na primer plesno-glasbeni tematski rokabilijski večeri v Orto baru ob sobotah, plesni večeri »swing 'n' rolla« v kavarni SEM ob torkih, nekdanji večeri balboe v Zelenem zajcu ob ponedeljkih itd. Vse to in še veliko več so prizorišča, ki so hkrati del drugih scen, a praviloma oblikujejo tudi povsem svoj krog zanesenjakov.. 
središče predstavlja Studio dansa, imajo raje starejšo glasbo 20., 30. in 40. let, v središču njihovega plesa pa je zvrst lindihopa; ${ }^{14}$ drugi, torej Swing kids in No sweat, pa so bolj usmerjeni v rock ' $n$ ' roll, rhythm \& blues, rockabilly in novo svingovsko glasbo ter mešajo številne svingovske plesne zvrsti, vendar vsaj za učenje novincev izhajajo iz $t$. i. six count svinga ${ }^{15}$ in vse pogosteje tudi sorodnega plesa bugivugi. Razlika med tema dvema scenama pa se ustvarja predvsem skozi glasbeni okus, saj se prvim zdi novejša glasba preveč »nabijaška« in za plesanje lindihopa premalo pestra, drugim pa se zdi starejša glasba preveč »cigu-migu « oziroma premalo energična in stimulativna.

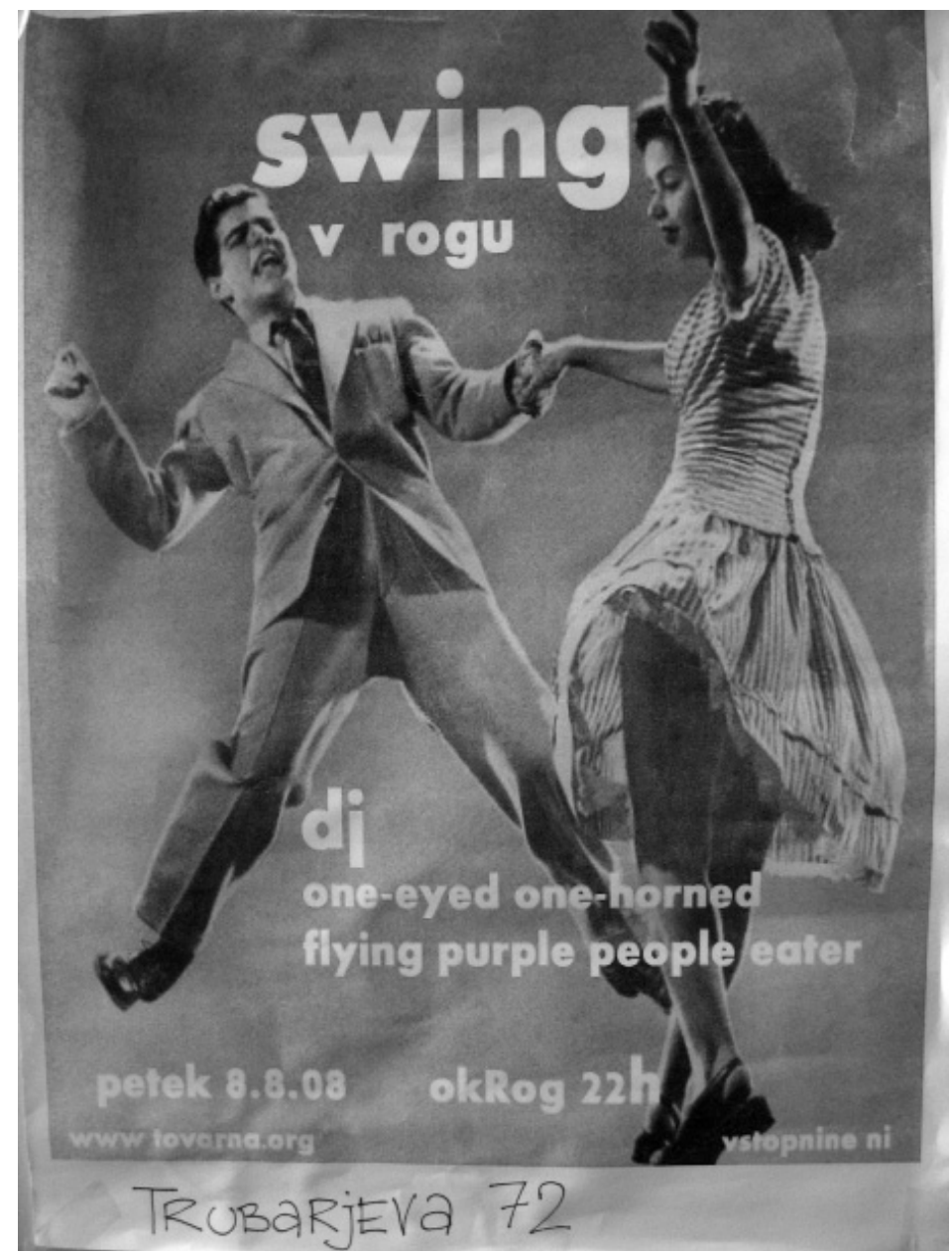

Slika 2: Plakat za svingovski večer rokenrolsko obarvane scene iz leta 2008. Foto: B. Kravanja.

14 Tako lindihop kot v nadaljevanju omenjeno balboo podrobneje obravnavam v besedilu spodaj.

15 Nekateri ta ples imenujejo tudi jitterbug, baby swing ali east coast swing. Ta ples je šestšteven in se ga je med svingovskimi plesi mogoče najhitreje naučiti. 
Poleg tega je znotraj prve scene vsaj za nekaj časa obetavno zaživela že omenjena posebna zvrst svinga balboa, ki se je za razliko od newyorškega lindihopa razvila na zahodni obali ZDA. ${ }^{16} \mathrm{~V}$ tem trenutku se balboa sicer poučuje, in sicer na obeh omenjenih scenah, nima pa rednih plesnih večerov. ${ }^{17}$ Podobno je z zvrstmi bluesa in west coast svinga: ${ }^{18}$ same plese $\mathrm{v}$ manjših zasedbah gojijo $\mathrm{v}$ okviru plesnih tečajev in občasnih delavnic, a ker zahtevajo svojo specifično glasbo, je udeležencev za plesne večere redno premalo. Tako se zopet občasno pojavijo v okviru lindihopskih večerov. ${ }^{19}$

Kljub vsem različicam v zvrsteh in okusu so svingovski plesi načeloma medsebojno kompatibilni, pri čemer pa je najbolj dominanten lindihop. Ta je od vseh svingovskih plesov najbolj odprt za vstavljanje različnih, v drugih plesih uveljavljenih plesnih elementov, improvizacij in inovacij. Tako se mora v praksi do lindihopa prej ali slej opredeliti vsak plesalec, saj se mu, prvič, brez znanja lindihopa nabor soplesalcev in scen precej zmanjša, drugič pa je lindihop tako kompleksen in hkrati fleksibilen, da plesalcem ponuja najboljšo osnovo za učenje svingovskih plesov nasploh. Morda je edina določnejša razlika pri bluesu, saj se tam zaradi zelo tesnega in razmeroma stalnega stika med plesalcema nabor stalnih soplesalcev izbira tudi po drugih, bolj osebnih ključih. V tem smislu so »samo-blues-plesalci« še najmanj nenavadni tudi $\mathrm{v}$ evropskem in ameriškem okviru. Za dominantnost lindihopa pa poleg njegove kompleksnosti in fleksibilnosti obstajajo zgodovinski razlogi, ki si jih bomo ogledali v nadaljevanju.

\section{Preporod »avtentičnega« lindihopa in vzpostavitev globalne svingovske scene}

Lindihop je nastal v newyorškem Harlemu, kjer je med letoma 1926 in 1958 delovala velika plesna dvorana Savoy (glej Engelbrecht, 1983; Hubbard in drugi, 2009; Spring, 1997). Njegova podlaga so afroameriški plesni slogi, kot sta bila

16 Nekateri zgodovinarji plesa verjamejo, da je predhodnik balboe čarlston, drugi collegiate shag, tretji fokstrot ali celo rumba. Balboa je ime dobila po polotoku pod Los Angelesom, kjer so ta ples v 20. in 30. letih plesali v enem od obmorskih letovišč (glej Balboa History, 2005). Podzvrst balboe je tudi bal-sving, ki je izšel iz svingovskih scen Los Angelesa in za razliko od čiste balboe, ki poudarja tesen stik med partnerjema, $v$ ta ples uvaja številne obrate in kroženje plesalca okoli soplesalke.

17 Pogosto pa se priložnost za balboo, ki se navadno pleše na hitrejše ritme (med 180 in 320 udarci na minuto), plesalcem ponudi na večerih z živo glasbo, ker imajo številne glasbene skupine v svojem repertoarju živahne dvečetrtinske skladbe. Na hitrejše ritme je sicer mogoče plesati tudi t. i. hitri lindi (angl. fast lindy) in (lindi-) čarlston, a daleč najudobnejši ples za to je balboa.

18 West coast sving je v 40. letih izšel iz lindihopa kot njegova stilizirana inačica in se danes pleše na zelo širok nabor popularnoglasbenih zvrsti, od bluesa, country glasbe, rock 'n' rolla pa vse do hip hopa, cool jazza in mainstreamovskega popa. V ZDA je precej bolj množičen od lindihopa, v Evropi pa (še) ne.

19 Na primer zadnjih nekaj skladb večera je pogosto bluzovskih. 
ragtime ${ }^{20}$ in čarlston, ${ }^{21} \mathrm{ki}$ so jih belci še $\mathrm{v} 20$. letih $\mathrm{z}$ rasističnim podtonom imenovali "ritmični«, "jazz« ali »moderni ples« (Monaghan, 2001, 125). Tako poimenovanje kot izvor lindihopa sta zavita v precejšnjo zmedo, ${ }^{22}$ pojavil pa se je sočasno z novimi tehnologijami snemanja in distribucije posnetkov ter tako postal prva ameriška moderna kultura popularne glasbe (Spring, 1997, 184; Engelbrecht, 1983, 7-8). Kot tak je bil tudi kulturno izhodišče, na katerem so se svetlopolti (in ne temnopolti) prebivalci ZDA začeli označevati kot »običajni« Američani (Usner, 2001, 94). Že druga generacija pionirskih plesalcev lindihopa je pomembno spremenila glasbeni izraz savoyskih big bandov ${ }^{23}$ ter med letoma 1935 in 1943 ustvarila t. i. zgodovinsko obdobje svinga (angl. swing era) (Hubbard in drugi, 2009, 129). Džezovska glasba, ki je bila dotlej večinoma označena kot »sladka«, je z lindihopom dobila svoje ritmično navdušujoče nasprotje: »vroči« jazz (Spring, 1997, 184, 202, op. 1; glej tudi Engelbrecht, 1983, 7-8).

Preporod svinga $\mathrm{v}$ ZDA in Evropi je povezan $\mathrm{z}$ delovanjem predvsem dveh starodobnih plesalcev lindihopa, Frankieja Manninga in Norme Miller (Renshaw, 2002, 73), ki sta leta 1986 na pobudo nekaterih newyorških mladih plesalcev začela na stara leta prvič v življenju poučevati ples. Zadeva se je najprej razširila na vzhodno in zahodno obalo ter drugod po ZDA. Leta 1987 pa je bil Manning povabljen tudi na Švedsko, kjer je kasneje v tamkajšnjem Herrängu nastal vsakoletni pet tednov trajajoči poletni Herräng Dance Camp. ${ }^{24}$ Posebni gostji Herränga sta vsako leto tudi omenjena Norma Miller in še ena legendarna oseba newyorškega Savoya, pevka in plesalka Dawn Hampton. Frankie Manning je leta 2007 objavil svojo avtobiografijo (Manning, 2007), leta 2012, ob tridesetem jubileju Herräng Dance Campa, pa so po njem poimenovali

20 O konstrukciji regtajmovskih plesov in vzajemnem prežemanju med plesi afroameriške in evroameriške skupnosti na sužnjelastniških plantažah ameriškega juga ter kasneje v urbanih središčih ameriškega severa glej George-Graves, 2009.

21 V času ameriške prohibicije alkohola (med letoma 1920 in 1933) je bil čarlston popularen tudi med premožnejšo belsko mladino v nelegalnih nočnih klubih. Njegove nove plesne elemente, kot na primer izolacije rok in drseče korake, je lindihop kasneje razvil v svojem najbolj prepoznavnem elementu swing outa (Monaghan, 2001, 125).

22 Ime lindihop se povezuje $\mathrm{z}$ anekdoto ob pionirskem poletu Charlesa Lindberga čez Atlantik leta 1927 (Engelbrecht, 1983, 4), a samo ime se je javno pojavilo šele petnajst mesecev kasneje (Hubbard in drugi, 2009, 131-133). Njegov najbolj znani ustvarjalec George »Shorty« Snowden je v nekem intervjuju v 50. letih izjavil, da je "prvi omembe vreden afroameriški ples, ki je bil ustvarjen na severu [ZDA], za razliko od prepričanja, da je prišel z juga kot del velike migracije na prelomu stoletja « (Hubbard in drugi, 2009, 133). Za nameček so newyorški plesni učitelji med drugo svetovno vojno ta ples imenovali jitterbug in trdili, da je lindihop zgolj ime za enega od njegovih korakov (Monaghan, 2001, 126).

23 Natančneje o izhodiščnem vplivu plesalcev na glasbo in ne obratno ter o kasnejšem vse tesnejšem prežemanju med glasbeniki in plesalci glej muzikološko analizo Howarda Springa (1997).

24 Leta 1982 se je začel kot enotedenski lokalni svingovski dogodek plesalcev stockholmskega Švedskega svingovskega združenja, danes pa je daleč največji in najbolj mednaroden svingovski plesni tabor na svetu (glej Herräng Dance Camp, 2014). 
glavno ulico, ki vodi skozi Herräng. Praznovanja Frankiejevih rojstnih dni od sredine 90. let spremljajo celotedenska praznovanja $\mathrm{v}$ New Yorku in številni lindihopski dogodki po svetu. Nadaljujejo se tudi po njegovi smrti (aprila leta 2009) in tako se spletni portal Youtube iz leta v leto polni s stotinami posnetkov plesanja koreografije Shim-sham-shimmy ${ }^{25}$ in posebnih letnih koreografij v slogu Savoy lindihopa. ${ }^{26}$

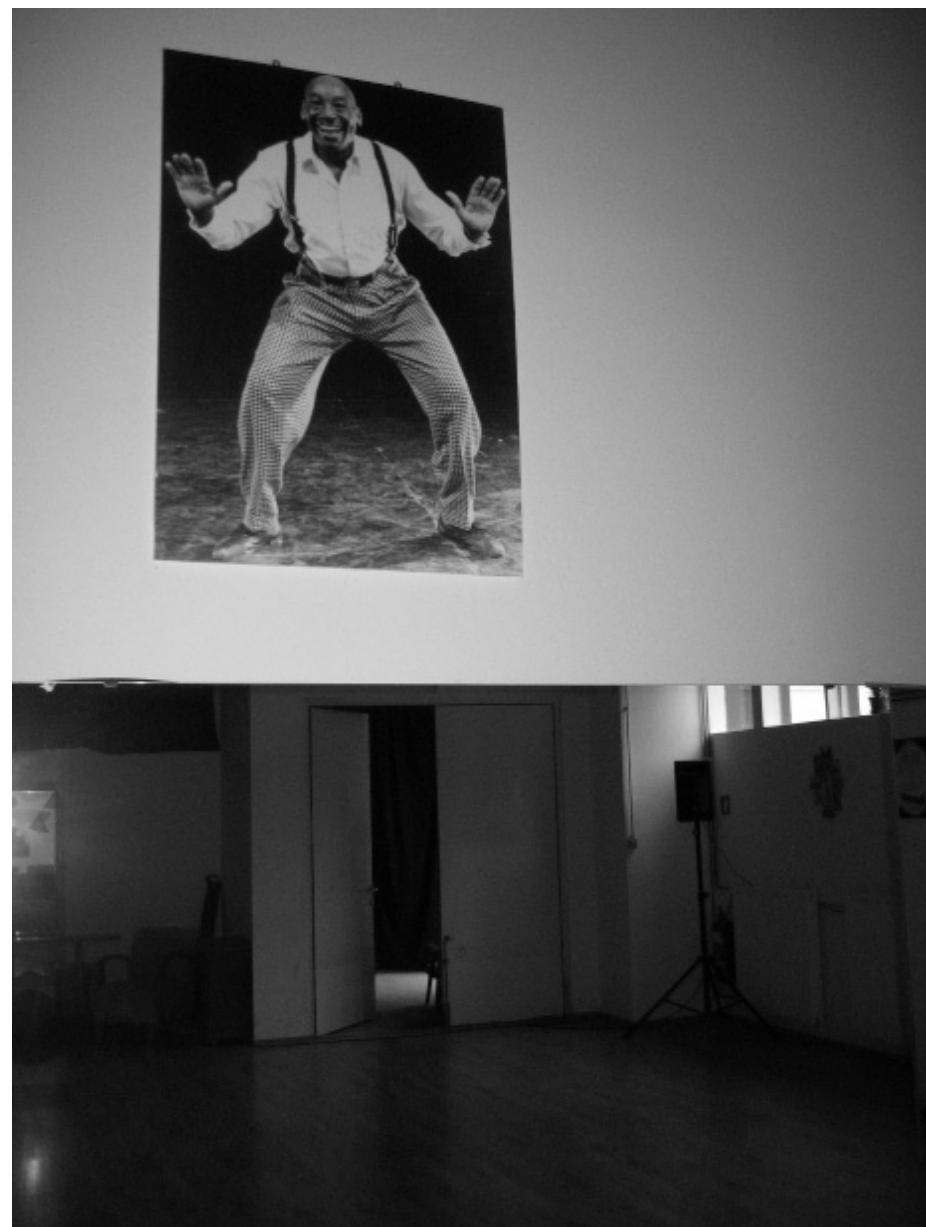

Slika 3: Plakat s podobo Frankieja Manninga v prostorih Studia dansa. Darilo zagrebških svingovcev ob otvoritvi decembra 2013. Foto: B. Kravanja.

25 Ta skupinska koreografija je ob še nekaterih drugih, kot na primer Big Apple, nastala v 30. letih na plesišču dvorane Savoy. Tranky Doo, še en danes popularen skupinski ples, pa je nastal v 40. letih (Hubbard in drugi, 2009, 136). Vsi ti skupinski družabni plesi, posebej pa Shim-sham-shimmy, so danes obvezen del svingovskih večerov na stotinah svingovskih družabnih plesišč po Evropi in ZDA.

26 Letos se je globalna svingovska skupnost učila koreografijo Frankie 100, ki jo je na nekem tečaju ustvaril sam Frankie Manning. Tako so jo 24. maja 2014 odplesali tudi slovenski svingovci v središču Ljubljane in naslednji dan v Celju. 
Oživljanja svingovskih plesov in lindihopa $\mathrm{z}$ zavzeto pomočjo starodobnih plesalcev (angl. old timers) ${ }^{27}$ ni mogoče površinsko razumeti samo kot »nostalgijo« po starih časih v ideološko homogeni skupnosti navdušenih plesalcev. Pristop k nostalgiji pri oživljanju svinga je bil namreč izrazito tehničen, razdelan in organiziran. Globalna svingovska skupnost se je vzpostavljala izrazito tržno ter pri tem s posnetki številnih nastopov in tekmovanj poskrbela za celostno podobo lindihopa kot vrhunske svingovske plesne zvrsti.

V tem smislu je svet sodobnega svinga tudi svet specifičnega zvezdništva, kjer je razmeroma ozek nabor ameriških in evropskih profesionalnih učiteljskih parov nenehno prisoten na globalni svingovski sceni. Ti mednarodni učitelji krožijo po različnih vikend festivalih, na katerih izvedejo povprečno od osem do dvanajst plesnih učnih ur, po dogovoru pripravijo skupinsko plesno točko, pogosto s posameznimi plesalci izvedejo zasebno učno uro, sodijo na tekmovanjih, opravljajo avdicije za razporeditev udeležencev $\mathrm{v}$ plesne ravni, nekateri vodijo večerne programe, od njih pa se tudi pričakuje, da se udeležujejo večernih zabav (navadno treh) in družabno plešejo z udeleženci festivala. Svingovski učitelji so $\mathrm{v}$ primerjavi $\mathrm{z}$ drugimi partnerskimi plesi med najslabše plačanimi plesnimi učitelji, ${ }^{28}$ pritisk nanje pa je poleg še drugih temnejših plati tega poklica (o tem glej Williams, 2011b) na festivalih velik predvsem s strani udeležencev.

Navzven so festivali videti kot en sam velik déjà $v u$, z vedno enakimi dopoldanskimi in popoldanskimi delavnicami in plesnimi večeri. Na delavnicah se udeleženci učijo figur ali specifičnega načina plesanja od učiteljev, ki jih vsaj nekaj že poznajo od drugod ali iz spletnih strani; na večerih plešejo na glasbeni repertoar, katerega vsaj polovico poznajo že iz domačih plesišč, prav tako pa so dokaj standardni tudi repertoarji bendov. Razlike med festivali se presojajo predvsem po njihovi velikosti: manjši in bolj intimni festivali gostijo okrog 100 ali 150 udeležencev, množični festivali pa 500 udeležencev ali več. ${ }^{29}$

Kar plesalce žene, da se udeležujejo teh ne preveč poceni prireditev, ${ }^{30}$ je seveda individualna izkušnja plesa. $\mathrm{Na}$ festivalih se poleg dela $\mathrm{z}$ vrhunskimi učitelji in gledanja

27 Frankie in Norma sta postala najvidnejša ikona sodobnega svingovstva, nista pa bila edina aktivna preroditelja iz prvih generacij lindihoperjev. To so bili še plesalci in plesalke, kot so Al Minns, Jewel McGovan, Dean Collins in še kdo.

28 Za učno uro na festivalu navadno dobijo od 110 do 130 evrov, organizator pa jim po dogovoru plača še nastop ter jim omogoči bivanje, prevoze in prehrano.

29 Največji vikend festival v Evropi je Lindy Shock v Budimpešti, ki je leta 2013 gostil 950 obiskovalcev iz več kot 35 držav, več kot trideset učiteljev in štiri bende (že omenjeni Herräng je še večji, vendar se odvija pet poletnih tednov). Med evropskimi festivali je zelo dobro zapisan tudi ljubljanski Sweet Swing festival (LSSF), ki je nazadnje, spomladi leta 2014, gostil okrog 350 udeležencev.

30 Za obisk mednarodnega vikend festivala mora udeleženec skupaj z vsemi stroški odšteti od 400 do 500 evrov. Skupnost si sicer prek dobro organizirane povezanosti na svetovnem spletu te stroške znižuje (gostiteljstvo, razdelitev skupnih prevoznih stroškov itd.), a samo festivalske vstopnice stanejo od 150 do 200 evrov. Cena rednega tedenskega tečaja je okrog 30 evrov mesečno, zasebne učne ure pa - odvisno od renomeja učitelja - stanejo 60 evrov ali več na učno uro. 
vrhunskih plesnih dosežkov predvsem v živo srečajo s plesalci iz različnih scen, ki jih v plesnem smislu še ne "poznajo«. Na družabnih plesiščih festivalov se prepleta nešteto raznolikih in intenzivnih izkušenj, želja, čustvovanj, vrednotenj in vzajemnih praks, ki posamezniku dajejo številne impulze in povratne informacije, na osnovi katerih si negotovo sestavlja lastno plesno vrednost. Družabno plesišče je, skratka, bistvo in motor svingovskih plesov, ki plesalce poganja, da pri tem početju vztrajajo ter vanj vlagajo svoj čas in denar.

\section{Družabno plesišče kot generator svingovske skupnosti in plesne nadarjenosti}

Družabni ples je ples določene skupine ljudi, ki se na organiziran način zbere, da bi nekaj praznovala ali slavila. Za razliko od odrskega, koreografiranega ali tekmovalnega plesa je družabni ples predvsem povezovalec skupnosti. Utrjuje lahko splošne družbene norme ali alternativne družbene ideje (Cohen-Stratyner, 2001, 121). ${ }^{31}$

Ideal svingovskega druženja je, da se na sceni $z$ glasbo in plesiščem vzpostavi communitas, kjer so udeleženci skupaj zgolj zato, da se zabavajo. Ta ideološkosolidarnostni vidik scen je seveda $\mathrm{v}$ interesu vseh, tako vodij in organizatorjev kot tudi samih udeležencev. Urejena ponudba, redni plesni večeri, informacijski portali, promocija, tečaji, lokalni festivali itd. udeležencem zagotavljajo pregleden in neproblematičen avtoritaren sistem, ki vključuje formalno razporeditev plesalcev po ravneh plesnega znanja, kar se ne nazadnje v obliki osnovnega nabora soplesalcev med »sošolci« $\mathrm{z}$ delavnic in tečajev reproducira tudi na družabnem plesišču.

$\mathrm{Z}$ rastjo posamezne scene pa se začne prakticiranje plesa odmikati tudi v odrske in tekmovalne oblike, k čemur logično spada tudi potreba po njihovem koreografiranju in poučevanju. Preboj v te polprofesionalne vrste pa ni samoumeven, saj se mora plesalec predhodno potrditi bodisi na festivalskih tekmovanjih ${ }^{32}$ bodisi s tem, da poleg splošne motiviranosti izkazuje »nadarjenost« za ples. Ta pa se, tako kot pri glasbi (glej Frith, 1996, 36-40), lahko določa in pripisuje v različnih kontekstih na različne načine: prvič, skozi odnos med učiteljem in učencem (visoko umetnostno okolje), drugič,

31 Poleg tega pojma obstajata še popularni in domači (vernakularni) ples, ki imata z družabnim veliko skupnega, opazne pa so tudi pomembne razlike. Tako lahko družabni plesi, ki v določeni generaciji veljajo za elitistične, v naslednji postanejo široko "popularni«. Večina družabnih plesov je v svojem bistvu »domačih«, saj izhajajo iz skupnosti ali subkultur in se neformalno prenašajo skozi družbenokulturne vezi itd. (Malnig, 2009, 4).

32 Tekmovalni formati v svingovskih plesih so: strogi format (angl. strictly), Jack and Jill, predstavitev (angl. showcase) in klasični format. Pri prvem formatu par pleše na različne hitrosti naključno izbrane skladbe, pri drugem se plesalci prijavljajo individualno in se partnerji za tekmovanje izbirajo naključno, pri tretjem par tekmuje s pripravljeno koreografijo, četrti pa je podoben tretjemu, le da $\mathrm{v}$ koreografiji niso dovoljeni določeni gibi, kot na primer skoki, solo vložki ipd. 
skozi institucionaliziran pomen (dobrega) plesa (popularno okolje) in tretjič, skozi dejstvo, s kom lahko posameznik pleše (džezovsko okolje). To vprašanje prepoznave nadarjenosti (in ne nadarjenost per se) je nenehen predmet stresa in paranoje udeležencev glasbenih šol (Frith, 1996, 38) ter plesnih skupnosti.

Na svingovskih scenah se nadarjenost plesalca prepoznava iz vseh treh omenjenih virov. Prvi tip najpogosteje obrodi sadove pri tistih učiteljih in plesalcih, ki so se znašli v vakuumu in iščejo stalnega plesnega partnerja, da bi se lahko z njim plasirali na tekmovalnem, odrskem in/ali učiteljskem trgu. ${ }^{33}$ Nadarjenost se tu prepoznava tako skozi učenje kot tudi skozi družabni ples in gledanje/občutenje soplesalčevega plesa.

Pri drugem tipu pripisovanja nadarjenosti je v ospredju pestrost, izvirnost in duhovitost različnih preobratov in prekinitev (angl. break) plesalca, plesalke pa v tem vrednostnem kontekstu bolj prepričajo z izvirnim slogom in elegantnostjo gibanja, ker so med plesom zaradi stalnega pošiljanja navzven ${ }^{34}$ bolj izpostavljene od plesalcev. Pri teh izhodih iz rutine je pomembno, kako se izvedejo in kombinirajo v ples in ne toliko njihova dejanska izvirnost. Postavljaški gibi (angl. show off move) so namreč del lindihopa, ${ }^{35}$ a če se na njihov račun zruši usklajenost med plesnima partnerjema, postanejo smešni. Subtilna meja med genialnostjo in smešnostjo, ki jo je Simon Frith $(1996,206)$ izpostavil pri nastopajočih v popularnokulturnem (na primer rokerskem) kontekstu, je na svingovskem plesišču postavljena dokaj visoko, saj so številni lindihopovski gibi precej nenavadni. Da jih plesalec zna uporabiti, je rezultat izkušenj (ali poguma), saj v drvečem toku plesa in glasbe ni časa za intelektualno presojo, ampak so odločitve hipne, najpogosteje pa tudi avtomatizirane. Tako pogosto tudi tisto, kar je videti kot invencija, ni nič drugega kot naučena improvizacija. ${ }^{36}$

Tretji tip pripisovanja nadarjenosti je na scenah najbolj negotov. Posebej pri plesalcu je namreč izrazito boljša soplesalka vir strahu pred tem, da jo bo dolgočasil (pri plesalki je to strah pred tem, da boljšemu plesalcu ne bo znala slediti pri izvedbi zahtevnejših figur), preveč pogumno (in selektivno) plesanje z boljšimi pa je lahko na sceni razumljeno kot vsiljevanje $\mathrm{v}$ krog elite. Tudi prehitro utiranje prijateljskih

33 Plesni učitelj pri nas zasluži od 90 do 130 evrov na mesec tečaja (to je štiri vaje) in okrog 100 evrov za plesni nastop izven okvira svingovskih scen.

34 V lindihopu se ti gibi imenujejo »send out « in »swing out«, v balboi (oziroma bal-svingu) pa »throw out« ali »toss out«.

35 Na voljo jih je cela vrsta in se jih poučuje kot "variacije«. Številni so bili v lindihop vneseni iz predhodnih plesov že v njegovi klasični dobi (na primer čarlston korak, Turkey Trot, Texas Thommy, Sailor Kicks itd.), nekateri pa se danes imenujejo tudi po njihovih izumiteljih (na primer Shorty George, Tacky Annie itd.).

36 O razmerju med invencijo in improvizacijo pri afriškem načinu glasbenega izvajanja in iz tega izvedenih popularnoglasbenih zvrsti glej tudi Frith s pripadajočimi citati (1996, 138-139). 
(ali ljubezenskih) vezi med elito, česar posledica je lahko tudi več kvalitetnega plesa, se lahko hitro razume kot solidarnostni ples elitnežev s sicer "nenadarjenim" posameznikom.

$\mathrm{Tu}$ je treba dodati, da med plesalci in plesalkami obstaja precejšnja razlika $\mathrm{v}$ načinu napredovanja, ki izhaja iz temeljne razlike med "slednikom " in "vodjo «. ${ }^{37}$ Novinke hitreje napredujejo od sovrstnikov, ker jih na plesišče takoj vabijo tudi boljši plesalci. Sledenja individualnim repertoarjem soplesalcev se učijo sproti ter tako tudi hitreje spoznavajo več plesnih situacij. Na vsakega soplesalca se postopno navadijo in lahko že vnaprej pričakujejo, kaj bo počel. Tovrstna habituacija za moške sploh ne obstaja, tako da novinci sovrstnice ujamejo šele kasneje, ko se prebijejo do kolikor toliko suverenega lastnega plesa. $\mathrm{V}$ tem smislu imajo ženske na družabnem plesišču boljše izhodišče za zgodnje vrednotenje svoje nadarjenosti glede na to, $s$ kom plešejo.

Poleg teh treh virov - učenec-učitelj, prevladujoč pomen dobrega plesa in nabor rednih soplesalcev - na prepoznavo nadarjenosti posredno vplivajo tudi hitrost napredovanja, telesna privlačnost in prisotnost na družabnem plesišču. ${ }^{38}$ Vsi ti dejavniki, ki ustvarjajo kariero vsakega plesalca ali plesalke $\mathrm{v}$ različnih poudarkih in kombinacijah, se tako ali drugače združujejo na družabnem plesišču. Tudi ko plesalec prodre med elito izrazito po prijateljskih ali ljubezenskih poteh, je končni rezultat navadno postopna prepoznava nadarjenosti plesalca, ker se k tovrstnim "neplesnim « razmerjem prej ali slej doda tudi odnos učenec-učitelj, temu pa sledijo razširitev kroga dobrih soplesalcev, prepoznava nadarjenosti na družabnem plesišču in slednjič nebesa - mesto plesnega učitelja.

Status plesnega učitelja v svingovskih scenah pomeni prestiž, plesalcu pa omogoči tudi več organizirane vadbe ( $\mathrm{z}$ učiteljskim partnerjem), pridobivanje drugačnega plesnega znanja (analiza gibov in nenehen stik $\mathrm{z}$ napakami učencev) in dostop do zastonjskega plesnega izpopolnjevanja (organizirana učiteljska vadba standardnih in odrsko pripravljenih koreografij). ${ }^{39} \mathrm{Ob}$ teh in številnih drugih zadolžitvah, ki so

37 O prevodu teh dveh, v mednarodnem svingu pogosto rabljenih pojmov (to je angl. leader-follower) so med slovenskimi svingovci že potekale (neuspešne) razprave. »Tradicionalno « poimenovanje za ti dve vlogi (ženske-moški ali dame-gospodje) je kompromis. Med ženskami je namreč zaradi pomanjkanja moških vse več vodij, skoraj vsi učitelji so vsaj približno zmožni plesati obe vlogi in nekateri moški se začnejo iz gole zabave učiti tudi sledniško vlogo.

38 Plesalcu se sicer z napredovanjem nabor zadovoljivih partnerjev logično oži, česar posledica je lahko, da pleše (vedno) manj. A, kot rečeno, njegova preveč očitna selektivnost se lahko razume kot vzvišenost oziroma povzpetništvo. Ples s slabšim soplesalcem je tudi poseben plesni izziv in se ga kot izhod iz vse ožjega prostora zadovoljstva oprijemajo tisti napredni plesalci, ki dajejo prednost golemu plesu in se poskušajo igram povzpetništva izogibati.

39 Tu se nanašam predvsem na razvite scene. Pri manjših scenah je teh zadolžitev in dodatnih možnosti sorazmerno manj. Bistveno pa je, da pridobitev mesta učitelja ni niti formalizirana v smislu avdicij niti posameznika načeloma nihče ne ovira, če na primer želi vzpostaviti svojo sceno in na svojo roko razpisati plesni tečaj. V kratki zgodovini svingovskih scen pri nas so se pogosto dogajale tako 
povezane $\mathrm{z}$ vzdrževanjem scene, nekaterim učiteljem zmanjka energije, da bi bili stalno prisotni še na družabnem plesišču. A tako kot pri mednarodnih učiteljih na festivalih je tudi na domačih scenah prisotnost na družabnem plesišču ena od nenapisanih dolžnosti učitelja. Poleg tega, da s tem kultivirajo dolgoročnejše odnose s svojimi tečajniki in jih tako lažje zadržijo na svojih tečajih, je družabni ples pogosto nadaljevanje učnega procesa v kontekstu plesišča.

Družabno plesišče torej večinoma sestavljajo učitelji in njihovi tečajniki oziroma sotečajniki različnih ravni, ki med seboj plešejo v vseh možnih kombinacijah po načelu vsesplošne ideološke solidarnosti med udeleženci scene. Številčni pa so na scenah tudi starejši plesalci, ki obtičijo nekje vmes: ne obiskujejo več tečajev, ker imajo, prvič, občutek, da se od obstoječih učiteljev ne morejo več naučiti ničesar bistveno novega, in drugič, ker jim je udeležba na tečajih skupaj z mlajšimi prišleki pod častjo.

Ti plesalci pogosto pomagajo pri podajanju plesnega znanja, če se na primer pojavi potreba po plesalcih enega spola (navadno primanjkuje moških), lahko se priključijo plesni skupini ali posamezni odrski koreografiji (če se izkažejo kot nadarjeni), ${ }^{40}$ lahko pa zgolj ostajajo na sceni in preprosto uživajo $\mathrm{v}$ plesu po svojih osebnih preferencah ( $\mathrm{t}$. i. cona udobja, angl. comfort zone). A to pri redkih traja v nedogled: pogosto se, če se ne začnejo ukvarjati z odrskimi variantami, ne dobijo stalnega partnerja ali ne začnejo učiti, iz scene postopno umaknejo in bodisi prenehajo aktivno plesati bodisi začnejo iskati nove plesne izzive na festivalih, $\mathrm{v}$ drugih plesih ali na drugih scenah.

Razvoj svingovskih plesov $\mathrm{v}$ smeri odrskih in tekmovalnih oblik ni samo vzporedna veja svingovstva, ki bi se razvijala ločeno od družabnega plesišča, ampak ga tudi pomembno dopolnjuje. Resda se družabno plesišče spontano vzpostavlja glede na glasbo in se ples v paru svobodno odvija glede na individualne preference plesalcev in plesalk, ${ }^{41}$ vendar pa plesne večere večinoma konvencionalno sestavlja tudi nekaj prekinitev, ki družabno plesišče na različne načine spremenijo v začasni oder z občinstvom. ${ }^{42}$ Danes so najbolj uveljavljeni štirje načini te spremembe: prvič,

odcepitve posameznih skupin, kot se tudi danes novi učitelji pogosto bodisi rekrutirajo bodisi samookličejo v manjših krajih izven Ljubljane, kjer se pač pojavita dovolj močna iniciativa in želja kakšne druščine po svoji sceni. Matične scene te iniciative načeloma podpirajo, saj s tem dolgoročno kultivirajo bazene za potencialne nove tečajnike tudi v lastni hiši.

40 Odrskih koreografij se sicer vse bolj lotevajo tudi na tečajih, da jih potem kot "produkcijo» predstavijo na sceni.

41 Po grobi oceni na podlagi lastne prakse in opazovanja drugih plesalec na en večer, ki traja od dve do štiri ure, odpleše od 14 do 24 plesov (torej po dva plesa s sedmimi do dvanajstimi partnerji). Tisti plesalci, ki so ves čas na plesišču, lahko redko dosežejo 30 plesov (le v enem primeru si je eden od v tujini živečih plesalcev na obisku »doma « zadal nalogo, da bo odplesal 50 plesov, kar mu je tudi uspelo), veliko pa je tudi takih, ki iz tega ali onega razloga plešejo manj.

42 V Savoyu so se te prekinitve imenovale »čas za predstavo« (angl. showtime). Navadno ga je naznanil bend s posebej "vročim « solo vložkom: ljudje so se zgrnili v krog ali polkrog, na sredini katerega so se izmenjevali elitni plesalci ter med seboj tekmovali v vedno novih izvirnih figurah in korakih (Engelbrecht, 1983, 6-7). 
pripravljeni nastopi plesnih skupin, učiteljev, gostov ali tečajnikov, drugič, občasna tekmovanja ob posebnih priložnostih, tretjič, t. i. svingovski improvizacijski krog (angl. swing jam circle), v katerem si naključni plesalci med plesom drug drugemu »izmikajo « člana ali članico skupnosti (najpogosteje, ko ima ta rojstni dan), in četrtič, skupno plesanje koreografije shim-sham-shimmy, ki navadno okrona konec vsake prekinitve in ki jo je mogoče odplesati na nešteto načinov, saj v okviru osnovnih gibov omogoča številne variacije. ${ }^{43}$

Meja med družabnostjo in razkazovanjem je torej na družabnem plesišču subtilna in večplastna. Plesalci na scenah niso samo plesalci, ampak tudi gledalci, hierarhije plesalcev pa se na scenah vzpostavljajo tudi skozi interesne skupine, ki svojo distinktivnost gradijo na okusu, občutjih pripadnosti in prijateljstvu. Ta vsebinska raven se za nameček bolj ali manj vedno prekriva s plesno ravnjo, kar pomeni, da se posamezne klike vzpostavljajo tako na podlagi plesnega znanja kot tudi na podlagi lojalnosti ter nejasno definiranega okusa (glej Bourdieu, 1984). ${ }^{44}$

Zaradi tega o strukturi plesnih scen ni mogoče govoriti samo v okviru formalne ideološke solidarnosti, ampak se vsaka scena pomembno sestavlja skozi (primarno plesne) prakse vzajemnosti. Te oblikujejo hierarhijo številnih skupin in skupinic, ki se s prihajanjem novincev neprestano spreminja. V tem smislu je družabno plesišče generator praktične solidarnosti svingovske skupnosti, ki za razliko od inkluzivnoideološke solidarnosti industrije svingovstva temelji na dinamičnih procesih neformalne hierarhizacije plesalcev in prepoznavanja njihove nadarjenosti v kontekstu učenja, konvencij vrednotenja in nabora rednih soplesalcev.

\section{Sklep}

$\mathrm{V}$ dveh vrstah solidarnosti, ideološki in praktični, s pomočjo katerih sem $\mathrm{v}$ pričujočem članku prikazal razpetost sodobne svingovske plesne skupnosti med plesnim studiem in družabnim plesiščem, je mogoče videti durkheimovski način obravnavanja skupnostne solidarnosti. ${ }^{45}$ Émile Durkheim $(1976$; 1997) je solidarnost

43 Refren skladbe Tain't What you Do džezovskega glasbenika Jimmyja Lunceforda (1939) - verzije, na katero se to koreografijo najpogosteje pleše - pravi, da ni pomembno, kaj počneš, ampak kako (kdaj, kje) to počneš. To lahko razumemo tudi kot splošni moto svingovskih plesov.

44 Na primer Scott Renschaw (2002, 76-78) je v svoji etnografiji svingovske plesne scene v ameriškem Phoenixu pisal o pravem razkolu med osrednjimi člani scene in "plesnimi piflarji«, kot so ti imenovali nove generacije plesalcev, ki so imeli po njihovem mnenju preveč sterilen pristop do plesa in scene.

45 Uporaba sociologije Émila Durkheima v raziskavah subkultur ni nekaj novega. Tako je na primer Ken Gelder $(2007,134)$ iz njegove klasične delitve skupnosti na "primitivne» in »moderne« izpeljal številne dvojnosti, kot so na primer konformnost in individualizem, primarno in sekundarno, elementarno in razkošno, golota in dodatki ter omejenost in presežnost, ki lahko pridejo v poštev pri obravnavanju sodobnih subkultur ali scen. 
delil na njene »elementarne« oblike (t. i. »mehanska solidarnost «) z močno »kolektivno zavestjo « in odsotnostjo kakršnegakoli individualizma ter oblike, ki temeljijo na delitvi dela, soodvisnosti, kooperativnosti ter individualni iniciativi in refleksiji (t. i. »organska solidarnost $«)$.

Nekateri avtorji so videli podobnost med Durkheimovo (1976, 5-6) stereotipnostjo gibanja v "primitivnih" skupinah in konformnostjo mišljenja ter potrebo po posnemanju v modi (G. Simmel po Gelder, 2007, 134-135), drugi so »mehansko solidarnost« videli v sodobnih »modernih plemenih» (M. Mafessoli po Gelder, 2007, 135-136). ${ }^{46}$ Po tovrstnih interpretacijah skupnosti je »zunanji svet odtujujoč in razočarajoč«, skupnost pa »svoje člane očara in ponovno seznanja $\mathrm{z}$ [izgubljeno] duhovnostjo, optimizmom in intimnostjo« (Gelder, 2007, 138).

V članku sem pokazal, kako svingovska skupnost izpolnjuje ta primarni vidik družbenega s precej tehničnim in izrazito tržnim pristopom k oživljanju "pristnega « džezovskega miljeja newyorškega Savoya, kar, paradoksno, prakticiranje plesa na eni strani oddaljuje od njegovega solidarnostnega ideala, na drugi strani pa se plesalci sami in drugače solidarizirajo na družabnih plesiščih. V tem sekundarnem oziroma »organskem« (Durkheim, 1997) vidiku svingovske solidarnosti je mogoče videti tudi fluidnost, minljivost in kompleksnost družbenih razmerij (na primer Zygmund Baumanova »tekoča modernost«) ali odprta in fleksibilna omrežja, pri katerih se namesto primarne skupnosti uveljavlja »jaz« kot simbolično ločena identiteta (po Gelder, 2007, 152).

Durkheimova "mehanska" in "organska" solidarnost in sorodne ideje konformnosti v množični kulturi modernih plemen ter tekoče modernosti in omrežij so teoretska orodja, s katerimi je mogoče razumeti svingovstvo na splošno, kot primer skupnosti v »siceršnji « družbi. ${ }^{47}$ Vendar je to premalo specifično, preveč posplošujoče. Šele prakse vzajemnosti ta osnovni okvir »skupnosti« pripeljejo k dejanskim procesom konstituiranja solidarnosti. Ta je bodisi ideološka, ko se nanaša na procese institucionalizacije in komercializacije svingovstva, bodisi praktična, ko se nanaša na procese porajanja vsakokratnega družabnega plesišča.

Ideološka solidarnost $\mathrm{z}$ avtoritarno hierarhizacijo plesalcev na plesne ravni zagotavlja pregleden sistem, v katerega se lahko varno vključi slehernik, v nagovarjanju širše javnosti pa ustvarja podobe privlačne atmosfere in visokega elitističnega standarda svingovskih miljejev ter nostalgične patine starih dobrih časov lepo urejenih gospodov in dam.

46 Mafessoli je za njihovo opredelitev uporabljal pojem »emocionalnih skupnosti«, ki so v svoji socializaciji obdržale »nekaj primitivnega « in »religioznega « v modernem urbanem kontekstu (po Gelder, 2007, 136).

47 Poenostavljeno rečeno gre torej za klasično delitev skupnosti Ferdinanda Tönniesa na Gemeinschaft in Gesellschaft (1975). 
Praktična solidarnost pa se spontano ustvarja skozi vzajemne plesne prakse in se na eni strani vzpostavlja kot »kolektivna zavest " skupnostne zabave (»mehanska» solidarnost), na drugi pa se poraja iz soodvisnosti med plesalci pri procesu plesnega napredovanja (»organska« solidarnost). $\mathrm{V}$ ta proces je poleg samega plesanja in pripadajoče medspolne porazdelitve plesnih vlog vključen tudi spreminjajoči se nabor bolj ali manj rednih soplesalcev in neformalne zaveze znotraj različnih skupin okusa.

Ker pa je svingovskih scen več in so notranje razdeljene, se ideološka in praktična solidarnost medsebojno prepletata. Prakse vzajemnosti med plesalci tako na različne načine prebijajo institucionalne okvire svingovstva in njegovih vsakokratnih scen, hkrati pa na družabnih plesiščih utrjujejo hierarhične odnose, ki jih ti institucionalni okviri generirajo s formalizacijo ravni plesnega znanja. Neformalne skupine in redni soplesalci se lahko upirajo institucionaliziranim oblikam poučevanja in udejanjanja svingovskih scen, kar lahko potencialno vodi do oblikovanja novih svingovskih scen, vendar temu utrjenemu okviru znanja nikoli ne uidejo v celoti.

Prakse vzajemnosti, paradoksno, prek ustvarjanja ekskluzivnih skupin bolj učinkovito prispevajo $\mathrm{k}$ ideološki solidarnosti svingovske skupnosti od njenih diskurzov splošne inkluzivnosti. Glede na opisane kontekste družabnega plesišča in generiranja prepoznave nadarjenosti plesalca so namreč te tiste, ki nenehno poskušajo presegati uniformno poučevanje svingovskih plesov in mu odrediti mesto »nujnega zla« za novince in za tiste, ki "pravega plesa ( širijo splošni okvir plesnega znanja na sceni, ki - idealno - povratno prehaja v plesne studie ali - praktično - utrjuje plesno hierarhijo.

Vendar lahko gremo pri tem še korak dlje. Plesišče resda vzpostavlja solidarnostne odnose med rednimi plesalci in neformalnimi skupinami, a redni plesni partnerji se vzpostavljajo tako rekoč ena na ena. V tem smislu stopijo v ospredje ne le prakse vzajemnosti na splošno, ampak biografije vzajemnosti posameznih plesalcev, ki jih ni mogoče vplesti v določeno strukturo ali omrežje, ker ni nujno, da ta za plesalca sploh obstaja mimo golih naključij in začasnih habituacij partnerstva.

Vsak ples je zgodba zase; če prakse vzajemnosti vzamemo zares, so vse solidarnosti in hierarhičnosti, ki se »na splošno« pojavljajo na scenah, zgolj prividi, ki jim plesalci podlegajo v svojih fantazijah o lastni vlogi in vlogi drugih na družabnem plesišču. Seveda imajo te percepcije in fantazije pomembne učinke, a specifika plesnih scen je v tem, da je ples temeljni način komunikacije in ne le medij ali »kultura «, ki omogoča siceršnjo komunikacijo. Na scenah sicer štejejo dejavniki splošne družabnosti, prijaznosti, bontona, zavisti, tekmovalnosti, pokroviteljstva in podobnih socialnih veziv in razdvajanj, a to, kar konec koncev zares šteje, so številne telesne vezi, ki jih plesalci in plesalke vzajemno kultivirajo na družabnem plesišču. 
$\mathrm{V}$ svojem generičnem in lacanovsko predpomenskem smislu te telesne vezi predstavljajo tisto vsebino plesnih scen, ki je sama po sebi prosta tako hierarhij kot tudi solidarnosti. Za razliko od v svingovstvu vse bolj prevladujoče tehnizacije plesa se to izhodišče namesto obsedenemu »napredovanju « posveča ustvarjanju vsakokratnega plesa. Na tej točki, na prehodu med »samo« preplesavanjem in "pravim« plesom, dolgoročno stojita ali padeta individualni plesalec in vsakokratna plesna scena. Pri prvem se to kaže v plesu za razliko od "plesnega piflarstva « (Renschaw, 2002, 77-78), pri drugi pa v plesni prisotnosti elite na družabnem plesišču za razliko od njenega pasivnega pozerstva ali odsotnosti.

\section{Viri in literatura}

Baggia, G., Swing kot subkultura in njegov tržni potencial. Diplomsko delo, Univerza v Ljubljani, 2008, http://dk.fdv.uni-lj.si/diplomska/pdfs/Baggia-Grega.PDF [15. 4. 2014].

Balboa History, http://www.lindycircle.com/history/balboa/ [19. 4. 2014].

Bourdieu, P., Distinction: A Social Critique of Judgement and Taste, London 1984 (1979).

Cohen-Stratyner, B., Social dance: Contexts and Definitions, Dance Research Journal 33 (2), Social and Popular Dance, 2001, str. 121-124.

Durkheim, E., The Elementary Forms of Religious Life, London 1976 (1912).

Durkheim, E., The Division of Labour in Society, New York 1997 (1893).

Engelbrecht, B., Swing at the Savoy, Dance Research Journal 15 (2), Popular Dance in Black America, 1983, str. 3-10.

Frith, S., Performing Rites: On the Value of Popular Music, Cambridge, Masachussetts 1996.

Gelder, K., Subcultures: Cultural Histories and Social Practice, Oxon, New York 2007.

George-Graves, N., »Just Like Being at the Zoo«: Primitivity and Ragtime Dance, v: Ballroom, Boogie, Shimmy Sham, Shake (ur. Malnig, J.), Urbana, Chicago 2009, str. 55-71.

Herräng Dance Camp: History and Philosophy, https://www.herrang.com/historyand-philosophy, 2014 [19. 4. 2014].

Hubbard, T. in drugi, Negotiating Compromise on and Burnished Wood Floor: Social Dancing at the Savoy, v: Ballroom, Boogie, Shimmy Sham, Shake (ur. Malnig, J.), Urbana, Chicago 2009, str. 126-145. 
Lindy Hop Today, http://en.wikipedia.org/wiki/Lindy_hop_today, 9. april 2014 [20. 4. 2014].

Malnig, J., Introduction, v: Ballroom, Boogie, Shimmy Sham, Shake (ur. Malnig, J.), Urbana, Chicago 2009, str. 1-15.

Manning, F. in drugi, Frankie Manning: Ambassador of Lindy Hop, Philadelphia 2007.

Monaghan, T., Why Study the Lindy Hop? Dance Research Journal 33 (2), Social and Popular Dance, 2001, str. 124-127.

Muršič, R., Trate vaše in naše mladosti, Ceršak 2000.

Renschaw, S. R., Postmodern Swing Dance and the Presentation of the Unique Self, v: Postmodern Existential Sociology (ur. Kotarba, J. A. in drugi), Walnut Creek, Boston, Oxford 2002, str. 63-85.

Reynolds, S., Retromania: Pop Culture's Addiction to Its Own Past, New York 2011.

Spring, H., Swing and the Lindy Hop: Dance, Venue, Media, and Tradition, American Music 15 (2), 1997, str. 183-207.

Swingopis podcast: Swing v Sloveniji z gostom Nejcem Zupanom, http://www. swingopis.si/p/blog-page.html [16. 5. 2014].

Tönnies, F., Community and Society, New York 1975 [1887].

Usner, E. M., Dancing in the Past, Living in the Present: Nostalgia and Race in Southern California Neo-Swing Dance Culture, Dance Research Journal 33 (2), Social and Popular Dance, 2001, 87-101.

Williams, N., Defining a Dance, http://www.swingnick.com/238/defining-a-dance/, 28. oktober 2011a [18. 5. 2014].

Williams, N., So You Want To Be a Traveling Lindy Hop Rock Star? (Part 1 of 2), http:// www.swingnick.com/196/so-you-want-to-be-a-traveling-lindy-hop-rockstarpart-1-of-2, 28. februar 2011b [18. 5. 2014]. 


\section{Boštjan Kravanja}

\section{Med plesnim studiem in družabnim plesiščem: O solidarnosti in praksah vzajemnosti v svingovskih plesnih skupnostih}

Ključne besede: plesne skupnosti, popularna kultura, solidarnost, hierarhični odnosi, prakse vzajemnosti

Članek z naslovom Med plesnim studiem in družabnim plesiščem: $O$ solidarnosti in praksah vzajemnosti $v$ svingovskih plesnih skupnostih razpravlja o dinamiki udejanjanja solidarnostnih in hierarhičnih odnosov v sodobnih plesnih skupnostih svinga. Pokaže, kako te skupnosti temeljijo na specifični solidarnostni ideologiji, ko obravnavamo procese njihove institucionalizacije, komercializacije in vzpostavljanja formalnih plesnih hierarhij. Ko pa $\mathrm{v}$ pogled zajamemo same plesalce in plesalke svinga, stopijo v ospredje raznolike prakse vzajemnosti, ki so za razliko od formalnih solidarnostnih diskurzov in praks veliko bolj heterogene in kot take tudi zanimivejše za antropološko obravnavo, saj vzpostavljajo solidarnostne in hierarhične odnose mimo širših mobilizacijskih vzgibov svingovske plesne industrije, prenekatere od njih pa se institucionalizaciji implicitno upirajo.

Teza prikaza tega primera je, da prakse vzajemnosti niso vedno vkomplementarnem razmerju z diskurzi solidarnosti, ampak je, prav nasprotno, v njihovi naravi, da glavne solidarnostne tokove pogosto zaobidejo in po svojih poteh, paradoksno, najbolj učinkovito prispevajo $\mathrm{k}$ dejanski solidarnosti vitalnih delov svingovskih skupnosti. Avtor je temo obdelal na podlagi šestletnega aktivnega sodelovanja na različnih slovenskih svingovskih plesnih scenah in občasne prisotnosti na mednarodnih svingovskih plesnih dogodkih po različnih evropskih mestih. 


\author{
Boštjan Kravanja
}

\title{
Between the Dance Studio and the Social Dance Floor: On Solidarity and Practices of Mutuality in Swing Dance Communities
}

Keywords: dance communities, popular culture, solidarity, hierarchical relations, practices of mutuality

This article discusses the dynamics of actualization of solidarity and hierarchical relations in contemporary swing dance communities. It shows how these communities are based on a specific solidarity ideology, at least it terms of dealing with processes of their institutionalization, commercialization and establishing of formal dance hierarchies. However, when we take into view the swing dancers themselves, diverse practices of mutuality become evident. In contrast to the formal solidarity discourses and practices, the latter are much more heterogeneous and as such more interesting for anthropological discussion, for they establish solidarity and hierarchical relations apart from wider mobilization movements of the swing dance industry, and many of them implicitly resist institutionalization.

The thesis arising from this case study is that the practices of mutuality are not always in complementary relation with discourses of solidarity. On the contrary, they often bypass the major solidarity flows and, paradoxically, contribute most efficiently to the actual solidarity of vital parts of the swing communities. The author discusses the subject on the basis of six years of active participation in different Slovene swing dance scenes and occasional presence at international swing dance events in different European cities. 